\title{
CERTAIN NUCLEAR GROUPS OF THE AVIAN MESENCEPHALON
}

\author{
ERWIN JUNGHERR \\ Department of Animal Diseases, Storrs Agrioultural Experiment Station, Storrs, Connecticut ${ }^{1}$ \\ FIVE PLATES (TEN FIGURES)
}

A study of the mesencephalon in the chicken has shown many interesting resemblances between the avian and the reptilian and the mammalian nuclear pattern in this region. The following account attempts to stress those likenesses by an application of mammalian terminology to certain nuclear groups in the avian midbrain. The pertinent literature will be considered in connection with the descriptions of the various areas.

\section{TECTAL AND SUBTECTAL REGIONS}

\section{Superior colliculus}

The superior colliculus or optic tectum in the bird is homologous with the similarly designated region in reptiles and mammals. However, in the bird there is a greater degree of layer differentiation than in these other forms. The general pattern of tectal lamination in submammals was first described by Ramón (1896), who differentiated fourteen layers in the lizard. He believed the lamination pattern to be similar in birds and his observations were confirmed by his brother Ramón $\checkmark$ Cajal ('11). In a restudy of the reptilian optic tectum Huber and Crosby ('33, '33a, '33b, '34) established six fundamental layers, found to be present in a wide range of reptilian forms, which they believed to have phylogenetic as well as functional justification (Huber and Crosby,

\footnotetext{
1 This study is a partial report on a cooperative project between the U. B. Regional Poultry Research Laboratory, East Lansing, Mich., and the Storrs (Conn.) Agricultural Experiment Station. It is based upon three Huber ('27) toluidin-blue stained sets of serial sections of the brain of the chicken, Gallus domesticus. namely a set of trangverse sections from an adult chicken, cut at 40 to $50 \mu$ and a set each of transverse and longitudinal sections from 4-day-old chicks cut at $25 \mu$. The author is indebted to the Huber Neurological Collection for the loan of an adult chicken set and in particular to Dr. Elizabeth C. Crosby, for her invaluable interest and help in this work and for extending the facilities of the Laboratory of Comparative Neurology, University of Michigan, during the summer of 1942. Mr. J. M. Levine, formerly associated with the Department of Animal Diseases, has been responsible for the preparation of the serial sections of the chick brains. Prof. G. S. Torrey and Dr. Rebecea Gifford kindly assisted in the preparation of the illustrations.
} 
'29). In certain reptiles and in birds, these authors considered the fundamental pattern to be amplified, due to a subdifferentiation of stratum griseum et fibrosum superficiale. Thus they created a comprehensive nomenclature for the tectal laminae for submammalian species and this nomenclature is applicable to the optic tectum of the chicken, with its highly subdifferentiated strata.

The fundamental strata are listed in order, from the surface to the ventricle (fig. 2). In the chicken, the submeningeal periphery of the tectum is formed by a poorly developed stratum zonale. Such a stratum is present in some reptiles and absent in others.

Stratum opticum, which lies immediately under stratum zonale, carries the incoming optic fibers. In the chicken this layer is delimited centrally by a thin but distinct band of small pale-staining neurons.

Stratum griseum et fibrosum superficiale is the receptive center of afferent tectal paths. It show a very high degree of secondary differentiation in the chicken, containing the greatest number of laminae of any of the tectal strata. From the surface inward the following secondary layers may be differentiated: (a) a cell-poor area underlying stratum opticum, (b) a broad band of pale-staining small neurons, (c) a cell-poor area in which fiber fascicles run, (d) a band of cells consisting of a row of linear, arranged, pale-staining neurons, a narrow, cell-poor fiber area and then a deeply situated line of linearly arranged, deeply staining cells so compactly arranged that their cell bodies cannot always be recognized. Internal to these bands, two others may still be differentiated: (e) a broad band of small scattered neurons and (f) a layer containing more closely arranged cell bodies. Finally, forming the innermost portion of stratum fibrosum superficiale, is a broad cellfree zone.

Stratum griseum centrale consists of a broad, somewhat irregularly delimited band of widely spaced, medium-sized neurons. These neurons are major contributors to the efferent tectal system.

Stratum album centrale, often termed stratum medullare profundum, is a wide fiber area underlying stratum griseum centrale. Through this white layer the main efferent pathways of the optic tectum run.

Stratum griseum periventriculare finds representation in the smallcelled gray intercalated close to the optic ventricle. Its neurons are so arranged that the dendrites spread toward the ventricle and the neuraxes either enter the efferent layer of stratum album centrale or pass toward the periphery of the tectum.

Stratum fibrosum periventriculare consists of fibers which circumscribe the ventricle. Into it come fascicles from the hypothalamus, the 
inferior colliculus and the cerebellum, and perhaps from other brain levels.

\section{Inferior colliculus \\ (Nucleus mesencephalicus lateralis pars dorsalis)}

Nucleus mesencephalicus lateralis pars dorsalis is considered to be the homologue of the mammalian inferior quadrigeminal body or the inferior colliculus (Huber and Crosby, '29). Sections through the superior colliculus present a group of medium-sized, pale-staining neurons, forming a considerable mass along the ventral aspect of the optic ventricle, from which it is separated by the periventricular gray and fibrous tectal strata (figs. 2 and 3). At levels through nucleus ruber, the inferior colliculus acquires deeper staining cells in its dorsal aspect (pars intramesencephalica of Groebbels, '24); the center shifts somewhat medially and its outline resembles a dorsally convex cupola (fig. 4). At more caudal levels, through the oculomotor nuclei, the inferior colliculus grades over into the periventricular gray (fig. 5). Throughout most of its extent the massive nucleus is accompanied on its more ventricular surface by a narrow fiber tract and by undifferentiated tectal gray. To express the association of the small-celled and large-celled pàrts, various authors, among them Craigie ('28, '30), have used the term torus semicircularis.

Nucleus pretectalis. This nucleus makes its appearance in the dorsolateral aspect of the diencephalon near its caudal end. It is in the form of a flattened oval, the dorsal pole of which is somewhat nearer the midline. In sections showing its full extent, it assumes a prominent melonlike architecture in that the medium-sized, deeply staining cells in the crowded center are surrounded by a thick, cell-free fiber capsule (fig. 2 ). In its rostral levels, it is laterally delimited by the tectal gray, ventrally and ventromedially by nucleus principalis precommissuralis, and dorsomedially by nucleus dorsofrontalis. More caudally its ventral pole comes into relation with pars lateralis of nucleus spiriformis (fig. 2 ). The structure terminates in the region of the tectal commissure. The pretectal nucleus has been described by many students of the avian brain since the early accounts of Edinger (1896, '08). Even earlier Turner (1891) had recognized this cell mass, terming it nucleus posterior. Accounts of nucleus pretectalis are to be found in the paper by Huber and Crosby ('29).

Nucleus subpretectalis. This nucleus which was recognized and named by Rendahl ('24) perhaps corresponds to Groebbels ('24) nucleus hypothalamicus posterior. It makes its rostral appearance at levels in 
which the nucleus pretectalis is already well developed (fig. 2). It lies in the ventrolateral aspect of the thalamus at the ventral end of the nucleus principalis precommissuralis. Laterally it is bounded by tectal gray, ventrally by the nucleus externus, and medially by the nucleus postrotundus. Anteriorly, it is of circular outline and reflects in certain sections the melon-like pretectal architecture, but the separation into fiber capsule and neurons is less distinct; furthermore the cellular elements are small, widely spaced, deeply staining polygons. In the posthabenular region the nucleus subpretectalis forms a large dorsomedially flattened oval, with its ventral pole nearer the midline (fig. 3). It reaches the farthest caudad of the pretectal complex, extending into the region of nucleus ectomamillaris.

\section{Nucleus isthmi}

Nucleus isthmi has been described by various observers. Cragie ('28) suggested its division into parvocellular and magnocellular portion.

Nucleus isthmi pars principalis magnocellularis. Ventral to the inferior collicular nucleus and its associated tectal gray, appears, at levels through the posterior commissure, a magnocellular group of neurons which constitute the rostal tip of nucleus isthmi pars principalis magnocellularis. In the planes in which it has reached its full development, it has essentially an elongated kidney shape with the hilus directed upward, and it maintains this form throughout its extent (fig. 4). However, the position of its long axis, which is horizontal in more rostral planes, changes as it gradually rotates around the hilus on the left and in a counter-clockwise direction on the right. The nucleus itself is shifted dorsally so that, in its most caudal position, it is dorsolateral to nucleus isthmi pars principalis parvocellularis.

Nucleus isthmi pars principalis parvocellularis. In planes in which the nucleus isthmi pars magnocellularis has reached full size in a ventral position, a dorsal group of paler and smaller cells, belonging to the nucleus parvocellularis, makes its appearance. At levels through the aqueduct, the ventral magnocellular portion and the dorsal parvocellular part are approximately of equal size in the chicken (fig. 4). More caudally the shift in the position of the magnocellular portion is accompanied by a similar shift in the parvocellular, but the latter increases in size markedly and assumes a long kite-like form (fig. 5). With the completion of the rotation of the isthmic nuclei, the size of the parvocellular part is reduced (fig. 6), its final position being medial to the magnocellular portion. Its most posterior tip can be located near the ventrolateral periphery of nucleus isthmo-opticus (fig. 7). 
Nucleus isthmo-opticus. In sections through the nucleus of the trochlear nerve, the dorsolateral aspect of the mesencephalon shows a prominent oval nucleus, the long axis of which parallels the mesencephalic surface; its architecture is characterized by the presence of medium-sized, deep staining multipolar cells. These cells are characteristically grouped into a row along the periphery and in condensed central clusters (fig. 7). The isthmo-optic nucleus is bounded medially by nucleus tegmentalis laterodorsalis, ventromedially by the nucleus mesencephalicus profundus, and ventromedially by the nucleus lemnisci lateralis dorsalis. In spite of its prominence, the nucleus does not reach farther back than the region of the trochlear decussation. This nucleus receives optic tract fibers. The other parts of nucleus isthmi are acoustic, being the recipients of fascicles of the lateral lemniscus.

Nucleus semilunaris. Just in front of the isthmo-optic nucleus, at levels through the nucleus of the oculomotor nerve, the lateral surface of the tegmentum exhibits a well defined band-shaped mass of mediumsized, deep staining neurons (fig. 6). This cell mass, nucleus semilunaris, comes into relation dorsally with nucleus lemniscus lateralis dorsalis and medially with nucleus mesencephalicus profundus. Its caudal tip is seen at levels which also present the caudal end of the trochlear nucleus.

Nucleus lemniscus lateralis dorsalis (Groebbels, '24). Sections through the rostral limits of the nucleus semilunaris show the dorsolateral aspect of the tegmentum to be occupied by a large, broad, sickleshaped mass of poorly staining small neurons. This nucleus lemnisci lateralis dorsalis (figs. 6 to 9 ) extends between the ventrally situated nucleus semilunaris and the dorsolateral corner of the tegmentum, and is bounded laterally by nucleus mesencephalicus pars principalis parvocellularis and medially by nucleus mesencephalicus profundus (figs. 6 and 7 ). More caudally, where the cells are condensed, it comes into dorsal relationship for a short distance with nucleus isthmo-opticus. It extends as an indefinite gray, intercalated in fiber bundles, into the medullary region to the level of the rostral pole of the chief sensory nucleus of $V$ (fig. 10).

Nucleus lemnisci lateralis ventralis (Groebbels, '24). In sections through the center of nucleus isthmo-opticus the region ventromedian to the nucleus semilunaris shows an indefinite group of medium-sized, somewhat deeply-staining, scattered neurons (fig. 7). Farther caudally, this structure develops into a broad oval (fig. 9), and can be traced into the anterior region of the medulla, where its position is taken up, within a few sections, by the prominent ventral cellular part of the chief sen- 
sory nucleus of $V$. This nucleus is interpreted as the ventral portion of the nucleus lemnisci but shows a difference in cytoarchitecture from the dorsal portion.

\section{NUCLEI OF THE POSTERIOR COMMISSURE}

Various nuclei at the transition line between diencephalon and mesencephalon, some lying in a subtectal others in a tegmental position, are either the recipients of posterior commissure fibers or discharge into that system or both. Certain of these, such as nucleus principalis precommissuralis described by Rendahl ('24), are more closely related to the diencephalon. Others, such as the pretectal and subtectal nuclei, have their major relations in the mesencephalon but are discussed elsewhere in this account. The following masses are grouped together under this heading for convenience of description.

Nucleus principalis precommissuralis has been described by Rendahl ('24), Huber and Crosby ('29), Craigie ('30, '31), Ariëns Kappers, Huber and Crosby (,'36).

Two parts of the nucleus spiriformis have been recognized by Edinger and Wallenberg (1899), Rendahl (as nucleus caudodorsalis, '24), Craigie ('28, '30) and Huber and Crosby ('29). The position, of the two parts in relation to each other, varies with the form considered.

Beccari ('23) described a nucleus dorsalis of the posterior commissure in reptiles. It appears to have representation in the chicken.

Nucleus principalis precommissuralis. Nucleus principalis precommissuralis lies immediately in front of the lateral portions of nucleus pretectalis and nucleus spiriformis pars lateralis. It extends forwara into diencephalic levels, lying rostrally lateral to nucleus rotundus (fig. 1). For part of its extent it is bordered laterally by a linear mass of gray, termed tectal gray (fig. 1) and illustrated by Rendahl ('24, fig. 72) under the caption "syncephalic-mesencephalic border."

Nucleus spiriformis pars lateralis. In rostral levels through nucleus pretectalis, there appears below its ventral pole a dense group of deeply staining magnocellular neurons which are oriented approximately parallel to the long axis of nucleus pretectalis (fig. 2). This group reaches full development in the immediate posthabenular region and resembles nucleus pretectalis in outline save for a lack of capsule. At this level the two nuclei are separated by posterior commissure fibers. Farther eaudally its horizontal diameter actually becomes larger, but the cells diminish in size and are more widely spaced. The posterior limits coinside with that of nucleus subpretectalis. 
Nucleus spiriformis pars medialis. Where the nucleus spiriformis pars lateralis shows typical development, its dorsal pole is a continuous line of medially extending neurons which constitute the rostral end of pars medialis (fig. 3). Farther caudad this group of cells thickens into a short band along the ventral aspect of fibers of the posterior commissure, and then becomes separated from pars lateralis. The separated pars medialis develops into a prominent kidney-shaped, large-celled nucleus which, at first glance, looks like nucleus pretectalis except for its sub- and intercommissural position. The last traces of the nucleus are observed in the region of the tectal commissure. It seems probable that this nucleus represents the nucleus magnocellularis of the mammalian posterior commissure.

Nucleus dorsalis of posterior commissure (Beccari, '23). This nucleus is similar to the nucleus of the posterior commissure of Edinger ('08) and Groebbels ('24). Rostral sections through the posterior commissure show the lateral portions of the commissural fibers interpolated with a considerable number of small pale-staining cells. This cellular group is situated medially from nucleus pretectalis and adjoins ventrally the nucleus spiriformis pars medialis (fig. 3 ). Posterior to the nucleus pretectalis, this intercalated gray increases in size and reaches its greatest extent in sections through the posterior and tectal commissures, where it completely surrounds the nucleus spiriformis pars medialis. Laterally the dorsal commissural nucleus is continuous with the stratum griseum periventriculare and the subcollicular gray of the optic tectum. In the postcommissural area, the nucleus loses its identity within the undifferentiated tectal gray. No large-cell equivalent for the nucleus interstitialis of the posterior commissure (Becarri, '23) has been observed in the chicken.

\section{THE NUCLEI AND ROOT FIBERS OF NERVUS OCULOMOTORIUS}

As found in the sparrow by Sanders ('29), the nuclear gray giving rise to root fibers of the oculomotor nerve may be subdivided into a chief nuclear group with a dorsolateral, dorsomedial and ventromedial subdivision and an accessory nucleus. Since the latter group has the more rostral representation, it will be discussed first.

The accessory group of the oculomotor gray, or the Edinger-Westphal nucleus, makes its appearance at planes through the rostral level of nucleus ruber (fig. 4). It lies in the periventricular region, appearing as a definite linear mass on either side of the midline. This is the rostral Edinger-Westphal nucleus, corresponding to the nucleus of the same name in mammals (Huber et al., '43). Slightly farther caudal- 
ward the nucleus becomes somewhat shorter and thicker and, with the appearance of the chief nuclear group, the accessory gray assumes a small-celled form (figs. 5 and 6). Here it is dorsal to the dorsomedian and dorsolateral portions of the chief nucleus. The dorsal shift of the large-celled oculomotor nuclear mass toward the ventral wall of the fourth ventricle marks the end of the caudal Edinger-Westphal nucleus.

The dorsolateral and dorsomedian divisions of the chief oculomotor nucleus come into evidence somewhat behind the most frontal root fibers of the oculomotor nerve. Medium-sized, intensely staining multipolar cells arrange themselves loosely along the short ventral extension of the aqueduct (fig. 5). As they become fully formed, these cells constitute the dorsomedial and dorsolateral divisions which lie adjacent to each other and then become continuous to form a conspicuous oval mass, which is bounded by the Edinger-Westphal nucleus above, and by the ventromedian portion of the oculomotor nucleus ventrally (fig. 6). Caudally, both of these groups pass over without any line of demarcation, into the nucleus of the trochlear nerve, approximately at the level of the nucleus isthmo-opticus (fig. 7).

The ventromedian group of the oculomotor nerve shows only one or two sections behind the rostral limit of the dorsal large-celled nuclear mass associated with this nerve, to which it then forms a ventral extension (figs. 5 to 7 ). Some of the neuraxons of this group decussate to the other side. At the transition level between the dorsal groups, the oculomotor, the trochlear and the ventromedian mass disappear. The large celled groups associated with the oculomotor nerve are sharply set off from the surrounding structures by the fibers of the medial longitudinal fasciculus (figs. 5 and 6 ).

The root fibers of the oculomotor appear rostrally in sections through the rostral Edinger-Westphal nucleus, where they are seen to emerge close to the midline, from the median ventral surface of the mesencephalon. The caudal limit of the roots is in a plane which still shows the full development of the four subdivisions of the chief nuclear group of the oculomotor (fig. 5).

THE NUCLEUS AND ROOT FIBERS OF NERVUS TROCHLEARIS

The gray forming the trochlear nucleus is continuous with the largecelled dorsomedial and dorsolateral groups of the chief nucleus of the oculomotor. It is noted in transverse planes through the rostral tip of the prominent isthmo-opticus (fig. 7 ). The trochlear nucleus shows a ventral concavity as it fits over the medial longitudinal fasciculus (fig. 8). It lies within the periventricular gray. A few sections caudal to the 
decussating fibers of the trochlear, the nucleus disappears being replaced by the dorsal portion of nueleus annularis.

The trochlear fibers appear to collect in the small fibrous area which expands immediately dorsolateral from the nucleus of the trochlear nerve (fig. 7). They run dorsolaterally and caudally to their short decussation in the isthmus region. Beyond the crossing, the trochlear nerve emerges from the brain surface just caudal to the optic tectum (figs. 6, 9 and 10).

\section{THE NUCLEUS RUBER REGION}

\section{Nucleus ruber}

This nucleus has been recognized for a long time and is considered to be homologous with the like-named magnocellular part of the mammalian formation. It constitutes an organized part of the nucleus reticularis mesencephalicus. In the chicken the red nucleus is represented by .very large, deeply-staining, scattered multipolar neurons, which are located centrally in the medial half of the mesencephalon (fig. 4). A few more rostrally extending cells may be seen at levels through the posterior commissure. The most compact formation lies in planes just behind the tectal commissure, but traces can be observed in more caudal sections which also show the chief nucleus of the oculomotor nerve (fig. 5).

Nucleus $X$. Nucleus mesencephalicus profundus. At levels through the rostral limit of the posterior commissure, one observes within the generally cell-poor posterolateral hypothalamic area an intercalated group of deep staining, medium-sized and often pyramidal shaped neurons (N. X, fig. 3), for which no taxonomic equivalent has been found. This group courses in an approximately diagonal direction toward the nucleus externus. (a small region formerly occupied by the nucleus posteroventralis). The group is laterally related to the fiber bundles in front of the pretectal nuclei. More caudally the formation disappears within a short distance after the appearance of nucleus ruber on its medial side.

Immediately posterior to the nucleus $\mathbf{X}$, just described, the lateral mesencephalic region shows undifferentiated relatively cell-poor gray. At levels of the caudal limit of nucleus subpretectalis, this undifferentiated gray begins to show infiltration with medium-sized, fairly deep staining neurons, for which, in analogy with mammalian nomeclature, the term nucleus mesencephalicus profundus is used (Huber et al., '43). Depending upon its topographic relationship to nucleus ruber, the 
scattered groups of the nucleus mesencephalicus profundus may be subdivided into a pars lateralis and a pars ventralis in the chicken. As the name is used here, it includes the ganglion mesencephali profundum laterale of Groebbels ('24) and its ventral part, the nucleus posthypothalamicus and nucleus tegmenti profundus of Groebbels ('24). This structure may include the cellular group for which Craigie ('30, p. 327) tentatively suggested the term nucleus tractus striotegmentalis.

The rostral portion of pars lateralis of nucleus mesencephalicus profundus is the most frontal representative of this nuclear gray and quite conspicuous at the level of the oculomotor nuclei and root fibers, where it is situated medial to the tip of nucleus isthmi pars principalis parvocellularis (fig. 5). Its disappearance coincides with that of nucleus ruber.

Pars ventralis is segregated at levels through the anterior root fibers of the oculomotor (fig. 5). In the cellular material it has a somewhat paler tint than that of pars lateralis, but resembles it otherwise. At this level pars ventralis is medially adjacent to nucleus interpeduncularis.

The more caudal portions of pars lateralis and pars ventralis reappear in the postruberal region (fig. 7 ). The lateral group shifts somewhat toward the midline, the ventral group has a tendency to assume a circular outline. At levels through nucleus isthmo-opticus, the cells of the lateral portion become gradually displaced by magnocellular elements of nucleus reticularis superior. The ventral portion is traceable to levels through the caudal end of nucleus annularis.

Nucleus tegmentalis laterodorsalis. Postcommissural sections through the rostral tip of the Edinger-Westphal nucleus and nucleus ruber show an undifferentiated gray immediately ventral to the aqueduct (fig. 4). Farther caudal, at levels through the chief mass of the oculomotor nuclei, this undifferentiated gray is organized into a definite small-celled nuclear group which stretches laterally from the Edinger-Westphal nucleus along the wall of the aqueduct toward the inferior colliculus (fig. 6 ). With the entrance of the nucleus isthmo-opticus, the nucleus tegmentalis laterodorsalis shows a marked lateral indentation (fig. 7) and terminates, only a few sections caudally to the former, at the level of the trochlear nucleus (figs. 8 and 9). In this region it is sharply separated from the laterally situated nucleus lemnisci lateralis by mesencephalic root fibers of $\mathrm{V}$ (fig. 8).

Nucleus tegmentalis dorsalis. The posterior limit of the above nucleus tegmentalis laterodorsalis is marked by the appearance of mediumsized, deep staining, polygonal or spindl-shaped cells of nucleus teg- 
mentalis dorsalis (fig. 9). Within a short distance these deep staining cells seem to form a lateral continuation of the dorsal portion of the nucleus annularis, but they persist beyond the latter nucleus in a position beneath the ventrolateral aspect of the fourth ventricle (fig. 10). The caudal limit falls into levels characterized by the presence of the sensory and motor nuclei of the trigeminal nerve and their associated roots.

Midline bed nucleus of the superior cerebellar decussation. This nucleus in the chicken appears rostrally in sections presenting a fully formed nucleus interpeduncularis (fig. 6). Dorsal to the latter, the fibers crossing the midline contain medium-sized, deeply staining, scattered cells. Within a short distance, these nuclear elements arrange themselves in the form of a triangle at either side of the midline, with the apex of the triangle pointing ventrally. Caudally this triangle is shifted upward and the cells spread, together with those of the nucleus annularis, along the ventral surface of the medial longitudinal fasciculus (fig. 7), constituting here possibly an avian equivalent of nucleus tegmentalis ventralis of von Gudden (see Craigie, '30, fig. 22).

Nucleus annularis. This nuclear formation which receives its name from its ring-shaped arrangement around the fasciculus longitudinalis medialis is not clearly distinct from the bed nucleus of the superior cerebellar decussation, but is of a smaller cell type than the latter. The anterior ventral portion of the cell mass, a possible homologue of the mammalian nucleus tegmentalis ventralis, consists of intermingled small and larger neurons underlying the ventral surface of the medial longitudinal fasciculus at the level of the trochlear nucleus and root (fig. 7). With the disappearance of the trochlear nucleus, the dorsal and lateral portions of the annular nucleus are in evidence and the ring is completed. In sections through the main extent of the nucleus tegmentalis dorsalis, the dorsal portion of the nucleus annularis is particularly well defined (fig. 9) and then disappears at the level of the chief sensory of $\mathrm{V}$ (fig. 10).

Nucleus linearis caudalis. At the forementioned point of juncture of the bed nuclei and the nucleus annularis, small, scattered, intensely stained cells of the annularis type continue ventrally on either side of the midline to form a possible nucleus tegmentalis ventralis. This cellular group is spoken of as nucleus linearis caudalis, since it corresponds in position and general relations with the nuclear group so designated in mammals. The picture of the nuclei lineares and annulares of both sides suggests the cross section of a funnel (fig. 8). More caudally, only seattered cells (fig. 10) remain of the nucleus linearis in levels which still show the dorsal portions of the nucleus annularis. 
Nucleus of the basal optic root (nucleus ectomamillaris). Sections through the fully developed pars medialis of nucleus spiriformis show the most rostral medium-sized, widely spaced multipolar neurons of the basal optic root nucleus (fig. 4). The number of neurons is small, but the cells are arranged within a large fibrous sphere, that is located next to the mammillary body on the ventral brain surface. Its principal relationship, on the dorsolateral periphery, is with nucleus externus. The nucleus disappears caudally at the level of the nuclei and root of III. This nucleus which has usually been termed the nucleus ectomamillaris in avian forms has been repeatedly described by students of the region (Edinger and Wallenberg, 1899; Kosaka and Hiraiwa, '15; Groebbels, '24; Huber and Crosby, '29 and others).

Ventral tegmental area of Tsai. Interpeduncular nucleus. At the rostral end of the mesencephalon, a few neurons, scattered in the median part of the area among the emerging rootlets of the ocolumotor, are the avian equivalent of the mammalian ventral tegmental area of Tsai (fig. 5). This region is replaced by an organized gray mass, the interpeduncular nucleus (fig. 6) which appears just caudal to the emerging rootlets of the oculomotor nerve and continues without definite boundaries into the undifferentiated gray at the base of the midbrain. The interpeduncular nucleus in avian (Craigie, '30) as in mammalian forms receives the habenulo-peduncular tract. The interpeduncular nuclear gray is characterized by small, closely arranged, poorly staining neurons, which in more caudal sections are assembled in dorsal and ventral groups that unite into a band-shaped structure at either side of the median raphé. Its dorsal limits are formed successfully by the oculomotor roots, the fibers of the superior cerebellar decussation, and the prominent bed nuclei of this decussation; its principal lateral relation is with the posterior part of nucleus mesencephalicus profundus pars ventralis.

\section{CONCLUSION}

The pattern of lamination seen in the avian superior colliculus is a further differentiation and subdivision of that characteristic for reptilian forms. The position of the inferior colliculus beneath the ventricle likewise suggests the situation of the comparable gray in such reptiles as the alligator. Separation of a common gray mass to form pretectal and subpretectal nuclei is undoubtedly associated with the lateral shift of this gray in coordination with the similar migration of the optic tract.

In the nuclear group to which the general term nucleus isthmi has been applied, there are included two fundamental types of centers. 
Nucleus isthmi, pars magnocellularis and pars parvocellularis are way stations in the course of the ascending lateral lemniscus and consequently, are a part of the central auditory system. Nucleus isthmoopticus, as its name implies, is related to the optic system, although there is no description of nucleus isthmo-opticus in reptilian forms. This nucleus is a conspicuous landmark in avian forms.

Nucleus spiriformis, pars lateralis has no known homologue in reptiles or mammals. Possibly, such a homologue exists but has not yet been recognized. The medial part of nucleus spiriformis often called nucleus caudodorsalis (Rendahl, '24) may represent the magnocellular portion of the posterior commissure as seen in some other forms.

As might be expected in animals with so well developed eyes, both the oculomotor and the trochlear centers are well differentiated. Rostral and caudal portions of the Edinger-Westphal nucleus, presumably comparable to similarly designated centers in mammals (Huber, et al., '43), are present in the chicken. The chief oculomotor group shows clearer subdivisions than are usually found in mammalian forms.

A magnocellular red nucleus has differentiated out of the avian reticular gray in the avian midbrain region. From this nucleus crossed fibers have been followed in birds as in mammals into the spinal cord, but their extent in the cord has not as yet been determined. In the regions lateral, ventral and caudal to the red nucleus of the chicken clusters of cells can be recognized. Lateral and ventral to the nucleus, these are spoken of as pars lateralis and pars ventralis, respectively, of the nucleus mesencephalicus profundus (Huber, et al., '43). Caudal to the plane of the red nucleus, postruberal portions of nucleus mesencephalicus profundus appear. These may well be forerunners of the caudal red nucleus, postulated by Huber and his associates ('43).

In the isthmus region a laterodorsal tegmental nucleus, a dorsal tegmental nucleus and an annular nucleus, comparable in a general way to the simlarly designated nuclei of mammals, have been identified.

A nucleus of the basal optic root, commonly known in avian forms as nucleus ectomamillaris (Huber and Crosby, '29), is highly developed in the chicken. At the base of the midbrain rostrally, scattered cells represent the mammalian tegmental area of Tsai. More caudally, a well organized interpeduncular nucleus receiving a well developed habenulopeduncular tract may be seen.

\section{LITERATURE CITED}

Ariëns Kappers, C. U., G. C. HubFr and E. C. Crosby 1936 The comparative anatomy of the nervous system of vertebrates, including man. The Macmillan Co., New York, 2 vols. 
Beccari, N. 1923 Il centro tegmentale o interstiziale ed altre formazioni poco note nel mesencefalo e nel diencefalo di un rettile. Archivio Italiano di Anatomia, vol. 20, pp. $560-612$.

Craigle, E. Horne 1928 Observations on the brain of the humming bird (Chrysolampis mosquitus Linn. and Chlorostilbon caribaeus Lawr.). J. Comp. Neur., vol. 45, pp. $377-483$.

1930 Studies on the brain of the kiwi (Apteryx australis). J. Comp. Neur., vol. 49, pp. $223-357$.

1931 The cell masses in the diencephalon of the humming bird. Proc. Kon. Akad. von Wetensch. te Amsterdam. vol. 34, pp. 1038-1050.

Eninger, I. 1896 Neue Studien über das Vorderhirn der Reptilien. Abhandl. d. Senckenb. nat. Gesellsch.; Frankfurt am Main, Bd. 19.

1908 Vorlesungen über den Bau der nervösen Centralorgane des Mensehen und

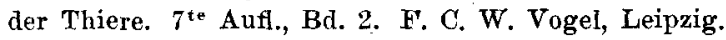

Edinger, L., and A. Wallenberg 1899 Untersuchungen über das Gehirn der Tauben. Axat. Anz., vol. 15, S. $245-271$.

Groebbels, F. 1924 Untersuchungen über den Thalamus und das Mittelhirn der Vögel. Anat. Anz., vol. 57, S. $385-415$.

HubER, G. C. 1927 A new method of fixation and staining of the central nervous system for purpose of study of eytoarchitecture. Contributions to Medical Science. Dedicated to Aldred Scott Warthin. Wahr. Ann Arbor, Michigan, pp. 1-12.

Hubbr, G. C., AND E. C. Crosby 1929 The nuclei and fiber paths of the avian diencephalon, with consideration of telencephalie and certain mesencephalic centers and connections. J. Comp. Neur., vol. 48, pp. 1-225.

1933a The reptilian optic tectum. J. Comp. Neur., vol. 57, pp. 57-163.

$1933 \mathrm{~b}$ A phylogenetic consideration of the optic tectum. Proe. Nat. Acad. Sci., vol. 19 , pp $15-22$.

1934 The influence of afferent paths on the cytoarchitectonic structure of the submammalian optic tectum. Psych. en Neur. Bladen, vols. 3 and 4, pp. 1-16. (Feestbundel Prof. C. U. Ariëns Kappers).

Huber, G. C., E. C. Crosby, R. T. Woodburne, L. A. Gilmilan, J. O. Brown and Bunliang TAMTHAI 1943 The mammalian midbrain and isthmus regions. J. Comp. Neur., vol. 78 , pp. 129-534.

Kosaka, K., AND K. HiRAIWA 1915 Zur Anatomie der Sehnervenbahnen und ihrer Zentren. Folia Neurobiol., Bd. 9, B. 367-389.

RaMón, P. 1896 Estructura del encéfalo del camaléon. Revista trimestral mierogrăfica, vol. 1, pp. $46-82$.

RAḾ́N Y CAJAL, S. 1911 Histologie du système nerveux de l'homme et des vertebres. 2 vols. A. Maloine, Paris.

Rendahl, H. 1924 Embryologische und morphologisch $\ominus$ Studien über das Zwischenhirn beim Huhn. Acta Zoologica, vol. 5, S. 241-344.

Sanders, E. B, 1929 A consideration of certain bulbar, midbrain, and cerebellar centers and fiber tracts in birds. J. Comp. Neur., vol. 49, pp. 155-222.

Turner, C. H. 1891 Morphology of the avian brain. J. Comp. Neur., vol. 1, pp. 39 and 107. 


\section{ABBREVIATIONS}

A. VENT. Teg. of Tsai, ventral tegmental area of Tsai

$A Q$, aqueduet

BED N. SUP. CER. DEC., midline bed nucleus of superior cerebellar decussation

COM. POST, commissura posterior

COM. POST. FIB, fibers of posterior commissure

F. L. M., faseieulus longitudinalis medialis

N. ANNUL. F. L. M., nucleus annularis of medial longitudinal faseiculus

N. R. BAS, OPT., nueleus of basal optic root (nucleus ectomamillaris)

N. DORS. COM. POST., nueleus dorsalis of posterior commissure (Beccari's)

N. DORSOMED. POST., nucleus dorsomedialis posterior

N. EXT, nucleus externus

N. GFNIC. LAT., nucleus geniculatus lateralis

N. HABEN, nucleus habenularis

N. INTERCAL., nueleus intercalatus

N. INTERPED., nucleus interpeduncularis

$\mathrm{N}$. IST. OPT., nucleus isthmo-opticus

N. IST. P. PRINC. MAGNOC., nucleus isthmi pars principalis magnocellularis

N. IST. P. PRINC. PARVOC., nucleus isthmi pars prineipalis parvocellularis

N. LEMN. LAT. DORS., nucleus lemnisei lateralis dorsalis

N. LEMN. LAT. VENT., nucleus lemnisci lateralis ventralis

N. LIN, CAUD, nucleus linearis caudalis

N. MAMILL. MED., nucleus mamillaris medialis

N. MES. LAT. P. DORS., nucleus mesencephalicus lateralis pars dorsalis (inferior colliculus)

N. MES. PROF. P. LAT., nucleus mesencephalicus profundus pars lateralis

X. MES. PROF. P, VENT, nucleus mesencephalicus profundus pars ventralis

N. R. MES. V., nucleus of mesencephalic root of $\mathrm{V}$

N. OC. ACCES., accessory group of oculomotor nucleus (Edinger-Westphal nucleus of III)

N. OC. DIV. DORSOMED, dorsomedial division of oculomotor nucleus
N. OC. DIV. DORSOLAT., dorsolateral division of oculomotor nucleus

N. OC. DIV. VINTROMED, ventromedian division of oculomotor nucleus

N. OVOID., nucleus ovoidalis

N. PERIVENT. ARC., nucleus periventricularis arcuatus

N. POSTEROVENT., nucleus posteroventralis

N. PRETECT., nucleus pretectalis

N. PRINC. PRECOM., nucleus prineipalis precommissuralis

N. RET. SUP., nucleus reticularis superior

N. ROT., nucleus rotundus

N. RUB., nucleus ruber

N. SEMILUN., nucleus semilunaris

N. SPIRIFO. P. LAT., nucleus spiriformis pars lateralis

N. SPIRIFO. P. MED., nueleus spiriformis pars medialis

N. SUBPRETECT., nucleus subpretectalis

N. SUPERFIC. PARVOC., nucleus superficialis parvocellularis

N. SUPERFIC. SYNENC., nucleus superficialis synencephali

N. TEG. DORS., nucleus tegmentalis dorsalis

N. TEG. LATERODORS, nucleus tegmentalis laterodorsalis

N. TR. HABEN. PED., nucleus of the habenulo-peduneular tract

N. TROCH., nucleus trochlearis

N. X, nucleus $\mathrm{X}$

POST. HYPOTHAL. A., posterior hypoth. alamic area

R. MES. V, mesencephalic root of $\mathrm{V}$

R. OC., root of oculomotor nerve

R. TROCH, root of trochlear nerve

SENS. N. V, chief sensory nucleus of $V$

STR. ALB. CENT., stratum album centrale

STR. FIB. PERIVENT., stratum fibrosum periventriculare

STR. GR. CENT., straum griseum centrale

STR. GR. ET FIB. SUPERFIC. stratum griseum et fibrosum superficiale

STR. GR. PERIVENT., stratum griseum periventriculare

STR. OPT., stratum opticum

STR. ZON., stratum zonale

TEC. GRAY, tectal gray

TR. N. OVOID., tractus of ovoidal nucleus 
All figures are photomicrographs of toluidin blue stained transverse sections of brain of adult chicken. $\times 20$. Some nuclei not deseribed in the text are labelled for orientation. The number in brackets indicates the position of the section in fronto-caudal sequence of the series used.

\section{PLATE 1}

\section{EXPLANATTON OF FIGURES}

1 (305) Through nucleus ovoidalis and nucleus rotundus.

2 (326) Through optic tectum and nucleus pretectalis. 

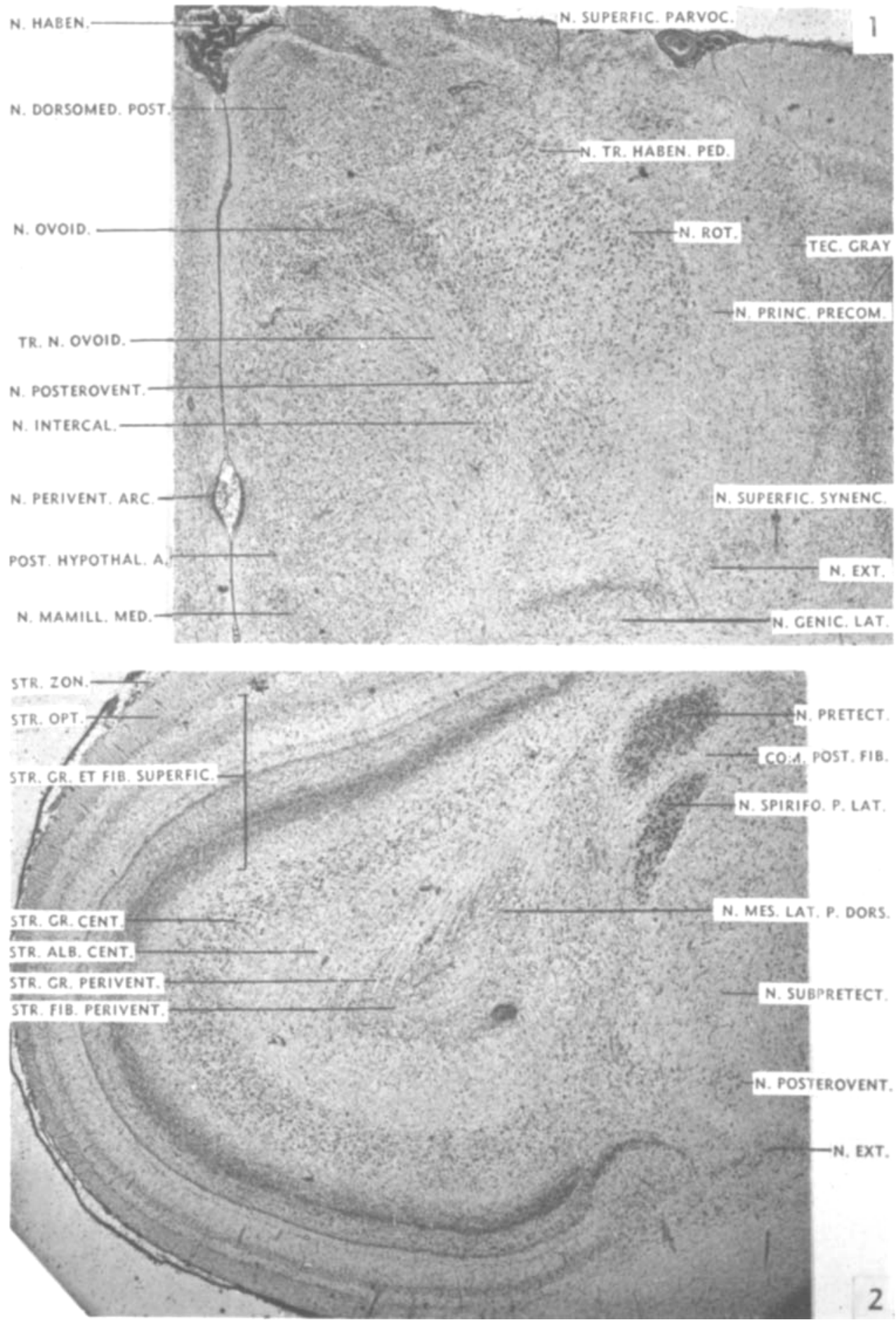
ERWIS JCNGHERA
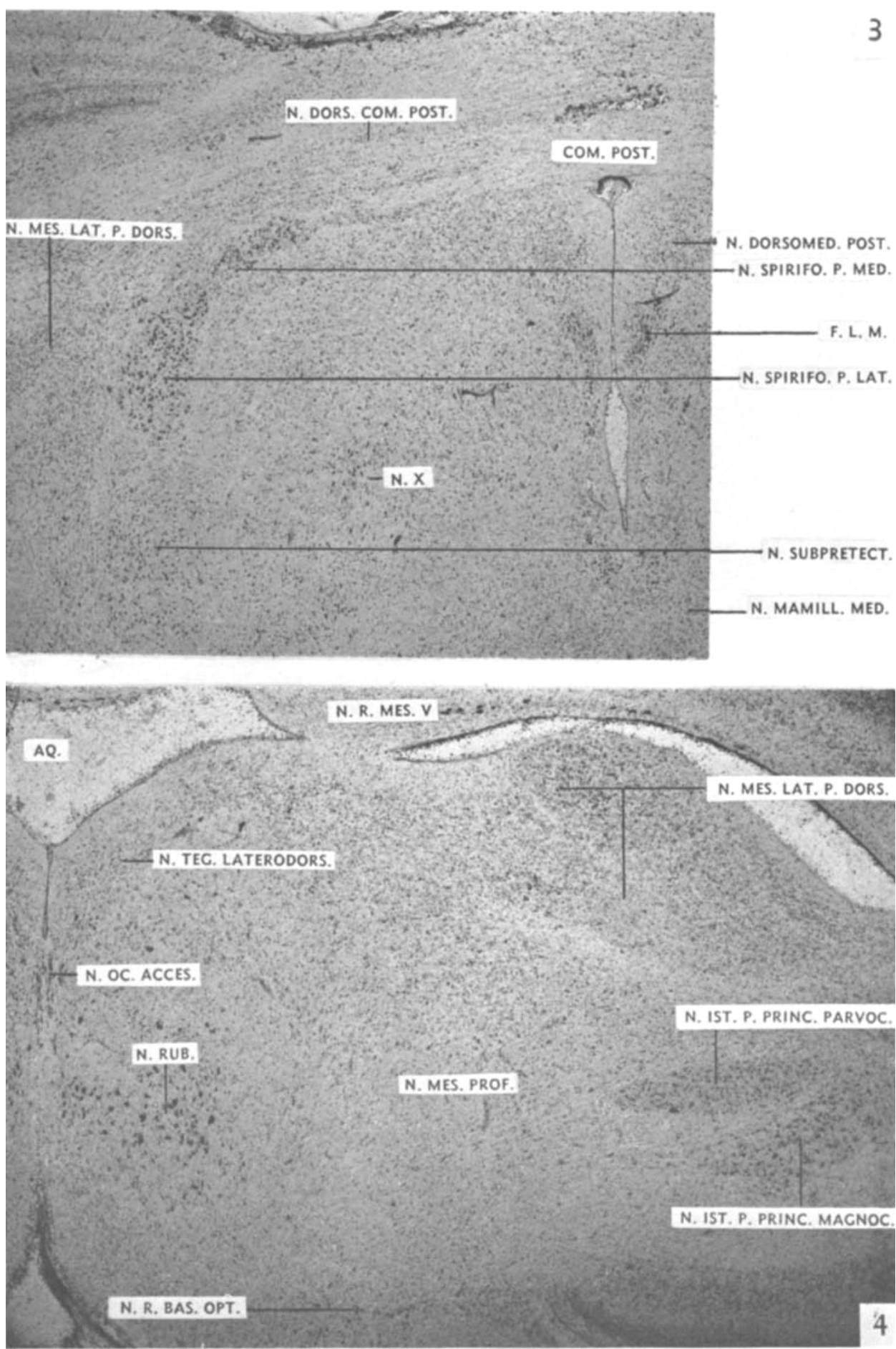

3 (347) Tlrough posterior commissure and nuclens spiriformis.

4 (373) Through inferior collieulus and nucteus ruber. 

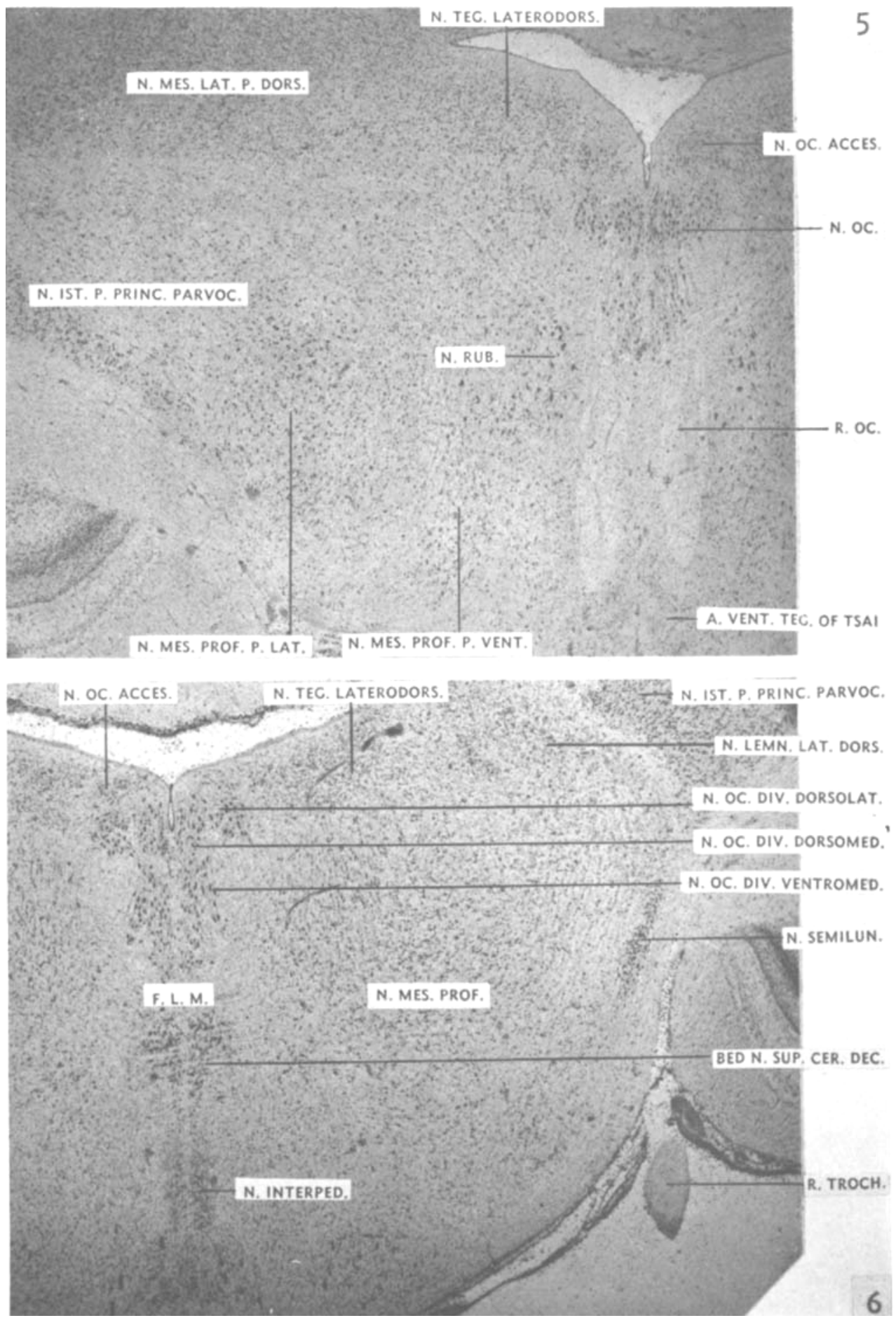

5 (410) Through oculomotor nucleus and root.

6 (437) Through oculomotor nuelens. 

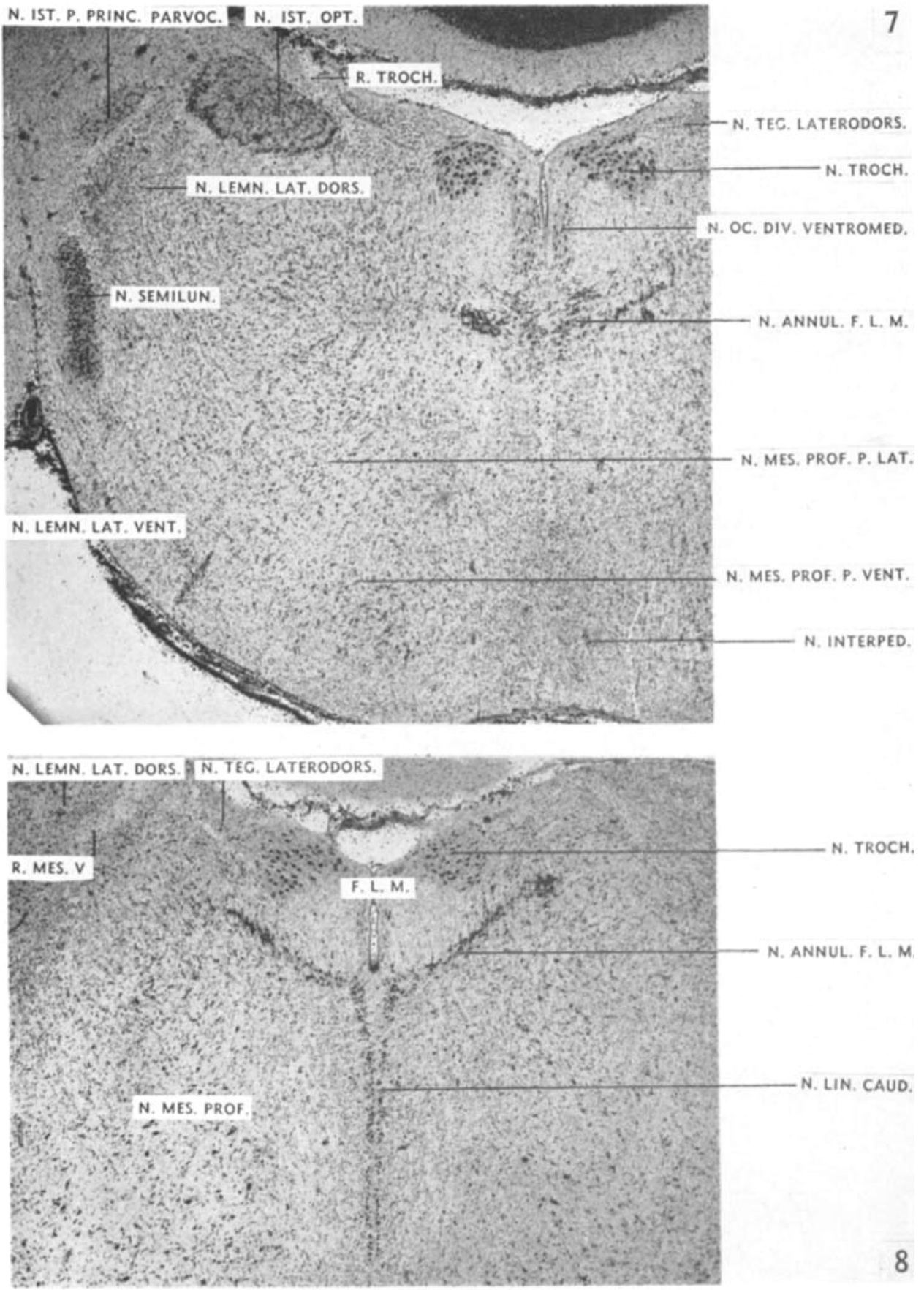

7 (446) Through trochlear nucleus.

8 (455) Through annular nucleus of medial longitudinal fasciculus. 

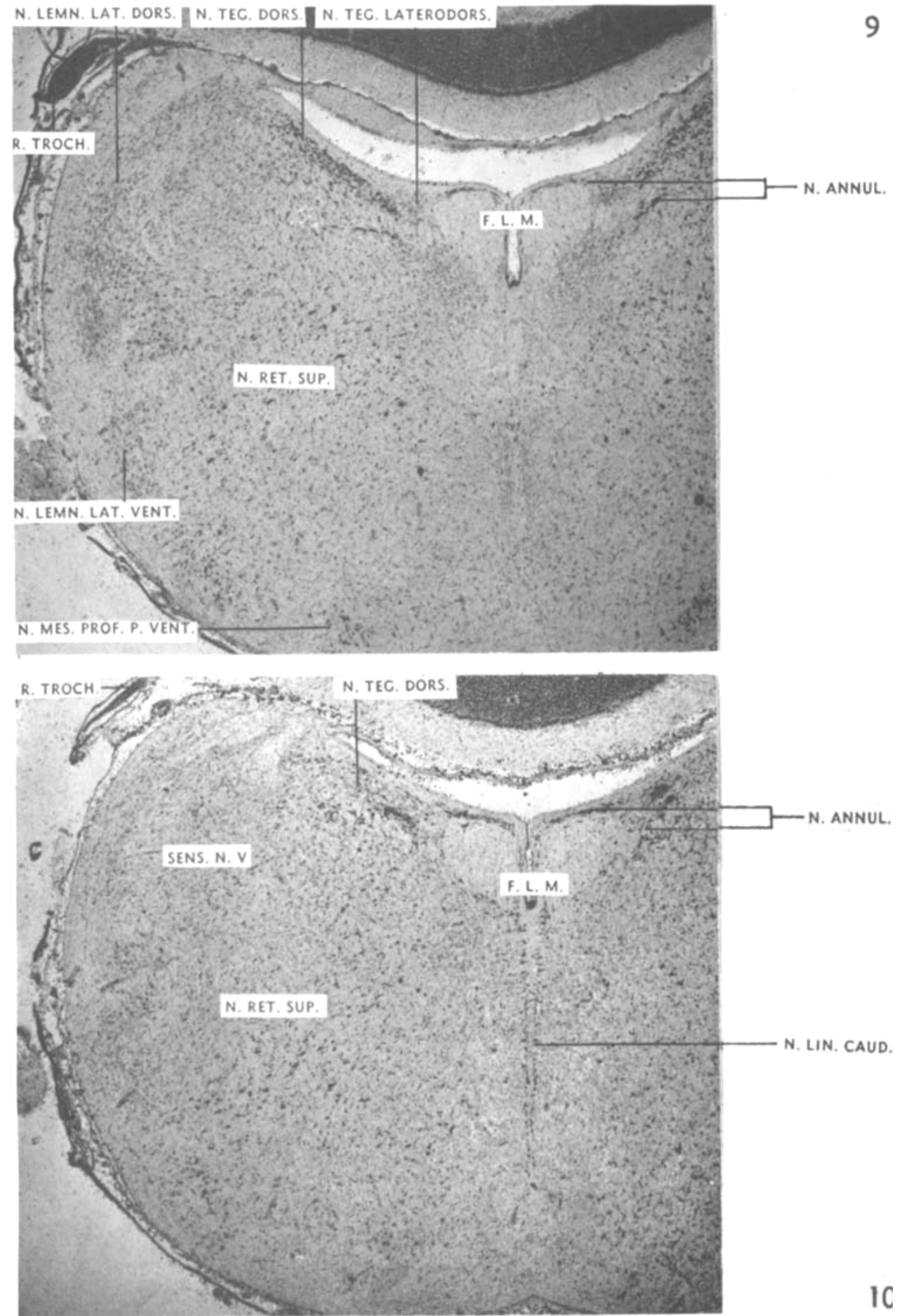

9 (472) Through nucleus lemnisci lateralis dorsalis.

10 (493) Through chief sensory nucleus of $\mathrm{V}$ and dorsal tegmental nucleus 